\title{
Interest rate volatility and macroeconomic dynamics: Heterogeneity matters
}

\author{
Michael Curran \\ Villanova University, michael.curran@villanova.edu \\ Adnan Velic \\ Technological University Dublin, adnan.velic@tudublin.ie
}

Follow this and additional works at: https://arrow.tudublin.ie/buschmarart

Part of the Business Administration, Management, and Operations Commons, and the Business Analytics Commons

\section{Recommended Citation}

Curran, M, Velic, A. Interest rate volatility and macroeconomic dynamics: Heterogeneity matters. Rev Int Econ. 2020; 28: 957- 975. https://doi.org/10.1111/roie.12477

This Article is brought to you for free and open access by the School of Marketing at ARROW@TU Dublin. It has been accepted for inclusion in Articles by an authorized administrator of ARROW@TU Dublin. For more information, please contact arrow.admin@tudublin.ie, aisling.coyne@tudublin.ie,gerard.connolly@tudublin.ie.

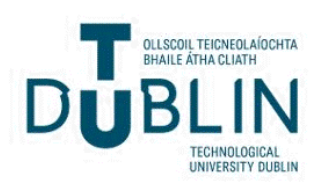




\section{Interest rate volatility and macroeconomic dynamics: Heterogeneity matters}

\section{Michael Curran $^{1}$ (D) | Adnan Velic}

\author{
${ }^{1}$ Economics Department, Villanova \\ School of Business, Villanova University, \\ Villanova, PA, USA \\ ${ }^{2}$ College of Business, Technological \\ University Dublin, Dublin, Ireland

\section{Correspondence} \\ Michael Curran, Economics Department, \\ Villanova School of Business, Villanova \\ University, 800 E Lancaster Ave, PA \\ 19085, USA. \\ Email: michael.curran@villanova.edu \\ Adnan Velic, College of Business, \\ Technological University Dublin, Dublin, \\ Ireland. \\ Email: adnan.velic@tudublin.ie
}

\begin{abstract}
We examine the relation between real interest rate volatility and aggregate fluctuations for a diverse sample of countries. Compiling a new dataset including emerging and advanced countries, the substantial variation in our data yields novel results: (a) stochastic volatility outperforms Markovswitching in representing interest rates, (b) some advanced economies can be more volatile than emerging markets, and (c) creditors take on more debt following volatility shocks. We show how an equilibrium business cycle model with uncertainty shocks can generate these facts. Sample heterogeneity produces significant parameter differences, playing an important role in distinguishing the effects of volatility shocks.
\end{abstract}

\section{JEL CLASS I F I CA T I O N}

C11; E13; E32; E43; E44; F41

\section{1 | INTRODUCTION}

How are the volatility of sovereign interest rates and macroeconomic variables related? We examine the relation between the volatility of real interest rates and aggregate economic performance for a diverse group of countries, arguing that sample heterogeneity is key to answering this question. Most research on the causes and consequences of country interest rate spreads focuses on movements in the level of these spreads (Ardagna, Caselli, \& Lane, 2007; Eijffinger, Kobielarz, \& Uras, 2015; Fahr, Motto, Rostagno, Smets, \& Tristani, 2013; Favero \& Missale, 2012; Laubach, 2009; Mody \& Sandri, 2012; Neumeyer \& Perri, 2005; Uribe \& Yue, 2006; Von Hagen, Schuknecht, \& Wolswijk, 2011). Expectations concerning the volatility of interest rates are important in managing the debt of a country. It is therefore surprising that few studies explore facts about changes in interest rate volatility. ${ }^{1}$ 
In the first part of the paper, we compile data on 27 calm and volatile emerging and advanced economies and establish empirical facts on interest rate volatility using a stochastic volatility model. On a country-by-country basis, we conduct time series investigations, finding that the stochastic volatility model better represents time-varying volatility of interest rates than other models such as the discrete Markov-switching model. Our empirical study of sovereign interest rate volatility is the first to compare the performance of these models across countries. Comparing models is important because our results lend credence to the choice of modeling time-varying volatility of interest rates with stochastic volatility.

We find that stochastic volatility shocks to country spreads are large and persistent overall. Across countries, nevertheless, we observe substantial heterogeneity. For example, while emerging markets on average display a higher degree of stochastic volatility than advanced countries, some advanced countries are more volatile than many emerging markets. This result runs contrary to expectations. In particular, volatility can be considerable for some euro area members such as Ireland, but less so for certain emerging economies such as the Philippines. We also observe that volatility increases at higher levels of country spreads, while it correlates negatively with measures of macroeconomic performance such as output, consumption, and investment.

In the second part of our paper, we demonstrate that an equilibrium business cycle model with uncertainty shocks can account for the empirical results. Using the estimates from our empirical stochastic volatility model, we calibrate the process for real interest rates and feed it into an otherwise standard small open economy real business cycle model. Altering interest rate volatility has a quantitatively notable effect on the dynamics of real variables, even when the real interest rate remains constant. In contrast to previous work, we examine heterogeneity across a broad range of countries by relaxing the assumption that the cost of adjusting debt must be identical internationally. That is, the fees households pay to investment banks handling debt differ across countries. As a result, our model benefits from an extra degree of freedom in matching the data. Substantial cross-country variation also produces significant parameter differences in the volatility parameters of the shock processes. We also update the computational procedures typically adopted in this literature, which leads to faster and more accurate estimation. Sample heterogeneity and improved computation alter results qualitatively. For instance, creditors acquire more debt assets following spread shocks and volatility shocks.

We can interpret higher volatility as capturing heightened uncertainty surrounding future events. Specifically, higher volatility can create financial uncertainty which has significant implications for business cycle fluctuations (Baker, Bloom, \& Davis, 2016; Curran \& Velic, 2020; Leduc \& Liu, 2016; Ludvigson, Ma, \& Ng, 2015). Higher volatility in sovereign debt markets enters our empirical model through a larger variance of shocks to the real interest rate. The study of volatility is particularly relevant for the analysis of crisis episodes and debt sustainability. A better understanding of the implications of volatility should assist policymakers in formulating more effective macroeconomic interventions.

Our work is closest in spirit to that of Fernández-Villaverde, Guerrón-Quintana, Rubio-Ramírez, and Uribe (2011) and García-Cicco, Naudon, and Heresi (2013). ${ }^{2}$ Both of these studies also adopt stochastic volatility models of interest rates and feed the estimates into equilibrium business cycle models. Real interest rate volatility detrimentally affects macroeconomic performance for Argentina, Brazil, Ecuador, and Venezuela (Fernández-Villaverde et al., 2011). Similar results hold for the case of Chile (García-Cicco et al., 2013).

Our study differs from these works in several ways. First, rather than imposing the econometric model, we empirically test which model better represents time-varying volatility of country spreads-a question that has received no attention. We find that the stochastic volatility model outperforms the discrete Markov-switching model. Second, our paper compiles a new dataset on sovereign bond yields that comprises a broader range of countries and a wider time dimension including both the Great Recession and the European sovereign debt crisis. The analysis of a diverse range of advanced and 
emerging market economies means that our calibration distinguishes between debtor and creditor nations, thus enabling an assessment of the impact of risk on countries facing different international financial positions. Third, we allow countries to face different costs of adjusting debt. This yields an extra degree of freedom in matching model moments with those of the data. While analyzing relatively homogenous countries can produce qualitatively identical results, our sample heterogeneity distinguishes between the various effects of volatility shocks. Fourth, we update the computational methods. By doing so, we ultimately switch the signs of certain results. For instance, creditors now accumulate debt assets with spread and volatility shocks.

On computation, our paper benefits from recommendations proposed by Born and Pfeifer (2014). To further improve computational accuracy, we also apply new results on third-order "pruning" for state-space models and compute "generalized" impulse response functions at the true "ergodic" mean (Andreasen, Fernández-Villaverde, \& Rubio-Ramírez, 2018). Moreover, we proceed a few steps further. Our paper employs "shell scripting" and exploits advances in high-performance computing which augment the efficiency with which computationally intensive tasks are executed. With many repeated experiments, scripts enable the automation of labor-intensive tasks. Scripts are useful in international macroeconomics since the cross-section dimension is normally large (Lane \& Milesi-Ferretti, 2007) and issues can be specific to particular countries and different experiments. Consequently, we develop multiple scripts that make use of "algorithmic parallelism" across CPUs and clusters of computers.

Our paper assumes that real interest rate volatility is exogenous. To a large extent, interest rate volatility shocks can be viewed as being mostly exogenous to the country. For instance, events in Greece and Italy may affect interest rates on Belgian debt through regime uncertainty. The objective of our paper is not to explain why real interest rate volatility changes over time, but rather how it changes. Studies on emerging markets (Akíncí, 2013; Longstaff, Pan, Pedersen, \& Singleton, 2011; Uribe \& Yue, 2006) and euro area members (Aizenman, Hutchison, \& Jinjarak, 2013; Balli, 2009; Barrios et al, 2009; Codogno, Favero, \& Missale, 2003) justify the empirical strategy of adopting an exogenous volatility process for real interest rate spreads on sovereign debt. Shocks orthogonal to country-specific fundamentals explain a large share of the variation in country spread movements. ${ }^{3}$

\section{2 | EMPIRICAL ANALYSIS OF REAL INTEREST RATES}

\subsection{Data}

We consider two groups of countries based on interest rate availability: (a) 15 emerging markets using JP Morgan's EMBI+ stripped spread (EMBIP) and (b) 12 euro area members (EA). ${ }^{4}$ We list the countries together with the periods and types of bonds covered in Table 1.

All bond maturities exceed one year and most bonds have a typical maturity of 10 years. We use monthly data as quarterly data smooth out too much of the volatility. We retrieve bond yields from Datastream. These data are available at daily frequencies and are converted to monthly figures by taking the end of period value. ${ }^{5}$ We express the real interest rate at which countries borrow internationally as the sum of a real country spread and a real international risk-free rate. We calculate the nominal country spread as the difference between the nominal yield on an EMBI+ or a sovereign bond and the nominal yield on a comparable international risk-free bond. We obtain real rates by adjusting for expected inflation, a moving average described in Section 1 of the technical appendix. For emerging markets the international risk-free rate is given by the yield on the U.S. T-Bill (RINTEMBIP). For euro area members the international risk-free rate is given by the yield on the German Bund (GermanyRINT). 
TA B LE 1 Country interest rate coverage

\begin{tabular}{|llll|}
\hline EMBIP sample & Time period & EA sample & Time period \\
\hline Argentina & 1993M12:2013M2 & Austria & 1997M12:2013M2 \\
\hline Brazil & 1994M4:2013M2 & Belgium & 1997M12:2013M2 \\
\hline Bulgaria & 1994M8:2013M2 & Finland & 1997M12:2013M2 \\
\hline Colombia & 1999M5:2013M2 & France & 1997M12:2013M2 \\
\hline Ecuador & 1995M2:2013M2 & Greece & 1998M8:2013M2 \\
\hline Indonesia & 2006M10:2013M2 & Ireland & 1997M12:2013M2 \\
\hline Mexico & 1993M12:2013M2 & Italy & 1997M12:2013M2 \\
\hline Panama & 1996M7:2013M2 & Malta & 2008M2:2013M2 \\
\hline Peru & 1997M3:2013M2 & Netherlands & 1997M12:2013M2 \\
\hline Philippines & 1999M4:2013M2 & Portugal & 1997M12:2013M2 \\
\hline Russia & 1997M8:2013M2 & Slovenia & 2007M4:2013M2 \\
\hline South Africa & 2002M4:2013M2 & Spain & 1997M12:2013M2 \\
\hline Turkey & 1999M7:2013M2 & & \\
\hline Ukraine & 2001M7:2013M2 & & \\
\hline Venezuela & 1993M12:2013M2 & & \\
\hline
\end{tabular}

Notes: EMBIP sample: yield difference of JP Morgan EMBI+ bond over a 3-month U.S. T-Bill; loans are denominated in U.S. dollars. EA sample: 3rd polynomial, constant maturity, stored yield curves on 10 year government bonds for loans denominated in Euros.

Source: Datastream. RINTEMBIP is the real international risk-free rate described in Section 2.1 and in Section 1 of the technical appendix. We chose periods based on the availability of bond yield data. Spreads are nominal. GermanyRINT is the real (inflation expectations adjusted) German 10-year government benchmark bid yield—it is the nominal version of this (dating back to 1990.09) for which spreads are relative to, for the EA sample. The HICP index used to compute expected inflation dates from 1997.12. We multiply average rates by 100 to be in percentages.

We source National Income and Product Account (NIPA) data from the IMF's IFS repository. Output is real GDP, consumption is private consumption expenditure and investment is the sum of gross fixed capital formation and changes in inventories. NIPA data is either in units of national (local) currency or in constant US dollars. To obtain real values we divide nominal ones by the GDP deflator or take constant value series. Real variables are deseasonalized using the US Census Bureau's X-12 ARIMA program and then logarithms of the deseasonalized data are detrended using a HP filter. We transform NIPA data from quarterly to monthly frequency to be in line with the periodicity of interest rates. In turn, we linearly interpolate corresponding monthly data to examine the relation between interest rate volatility and macroeconomic dynamics. ${ }^{6,7}$

\subsection{A stochastic volatility model}

Stochastic volatility models typically specify an autoregressive (AR) process for the logarithm of volatility, defining volatility as the standard deviation. We focus on a univariate stochastic volatility model in which country spreads and log volatility each follow an AR(1) process with drift. As implied, we conduct exercises country-by-country. We decompose the real interest rate of a country at time $t$ into the average real interest rate of the country over time, $r$, a time-demeaned country spread, $\epsilon_{r, t}$, and a time-demeaned international risk-free real rate, $\epsilon_{t b, t}$. So, 


$$
r_{t}=r+\epsilon_{r, t}+\epsilon_{t b, t}
$$

Let $\left\{u_{i, t}\right\}_{i \in\{r, t b\}}$ and $\left\{u_{\sigma_{i}, t}\right\}_{i \in\{r, t b\}}$ be standard Normal innovations. The innovation $u_{\sigma_{i, t}}$ is called the stochastic volatility shock. The parameter $\rho_{i}$ is the degree of persistence in the interest rate level, while $\rho_{\sigma_{i}}$ is the degree of persistence in volatility. The parameter $\sigma_{i}$ is the mean volatility and $\eta_{i}$ influences the degree of stochastic volatility. The laws of motion for $\epsilon_{r, t}$ and $\epsilon_{t b, t}$ are

$$
\begin{gathered}
\epsilon_{r, t}=\rho_{r} \epsilon_{r, t-1}+e^{\sigma_{r, t}} u_{r, t}, \\
\epsilon_{t b, t}=\rho_{t b} \epsilon_{t b, t-1}+e^{\sigma_{t b, t}} u_{t b, t}, \\
\sigma_{r, t}=\left(1-\rho_{\sigma_{r}}\right) \sigma_{r}+\rho_{\sigma_{r}} \sigma_{r, t-1}+\eta_{r} u_{\sigma_{r}, t}, \\
\sigma_{t b, t}=\left(1-\rho_{\sigma_{t b}}\right) \sigma_{t b}+\rho_{\sigma_{t b}} \sigma_{t b, t-1}+\eta_{t b} u_{\sigma_{t b}, t} .
\end{gathered}
$$

Equations (2) and (4) describe the process for country spreads, while Equations (3) and (5) describe the process for the real international risk-free rate. ${ }^{8}$ Two shocks, $u_{i, t}$ and $u_{\sigma_{i}, t}$ hit $\epsilon_{i, t}$. The innovation $u_{i, t}$ affects the level of the rate in question and the innovation $u_{\sigma_{i}, t}$ affects the standard deviation of $u_{i, t}$. In the baseline version of the model, innovations to the level of the series, $u_{i, t}$, are independent to innovations to the volatility of the series, $u_{\sigma_{i}, t}$. That is, for each $i \in\{r, t b\}$ and for each $j \in\{r, t b\}, u_{i, t}$ is independent of $u_{\sigma_{j}, t}$. Since country spread levels might be correlated with volatility, we also estimate the model under a correlation between $u_{r, t}$ and $u_{\sigma_{r}, t}$.

We estimate our model using Bayesian techniques. Our estimation employs the bootstrap particle filter, which we nest within the Metropolis-Hastings algorithm. The estimates are subsequently fed into a DSGE model. Table 2 displays country-specific priors employed. ${ }^{9,10}$

\section{3 | Model comparison}

In the macroeconomic literature, other popular models of time-varying volatility include GARCH and Markov-switching models. ${ }^{11}$ Level and volatility shocks cannot be isolated in the GARCH class of models as one shock drives both the level and volatility of interest rates. The choice between stochastic volatility and Markov-switching models is an empirical question as there are theoretical advantages and disadvantages to using each over the other. ${ }^{12}$ A review of the literature reveals that no study has considered this issue in the context of representing time-varying volatility for country spreads. To fill this gap, we estimate a comparable two-state Markov-switching variance AR(1) model and use Bayesian log posterior odds to provide a relative test of whether stochastic volatility models are the best representation of time-varying volatility for spreads for all 27 economies and the risk-free international rates. ${ }^{13}$ The Markov-switching model is given by

$$
\begin{aligned}
& \epsilon_{t}=\phi_{1} \epsilon_{t-1}+e_{t} \quad e_{t} \sim \mathcal{N}\left(0, \sigma_{t}^{2}\right) \\
& \sigma_{t}^{2}=\sigma_{1}^{2} S_{1 t}+\sigma_{2}^{2} S_{2 t} \sigma_{1}^{2}<\sigma_{2}^{2} \\
& S_{j t}= \begin{cases}1 & S_{t}=j \quad j=1,2 \\
0 & \text { else }\end{cases} \\
& P\left(S_{t}=j \mid S_{t-1}=i\right)=p_{i j} \quad i, j=1,2 \quad p_{i 1}+p_{i 2}=1
\end{aligned}
$$


TA B L E 2 Priors for parameters of the stochastic volatility model

\begin{tabular}{|llll}
\hline Country & $\sigma_{\boldsymbol{r}}$ & Country & $\sigma_{\boldsymbol{r}}$ \\
\hline Argentina & $\mathcal{N}(-5.3,0.4)$ & Mexico & $\mathcal{N}(-7.3,0.4)$ \\
\hline Austria & $\mathcal{N}(-9.5,0.4)$ & Netherlands & $\mathcal{N}(-9.9,0.4)$ \\
\hline Belgium & $\mathcal{N}(-8.9,0.4)$ & Panama & $\mathcal{N}(-8.0,0.4)$ \\
Brazil & $\mathcal{N}(-6.8,0.4)$ & Peru & $\mathcal{N}(-7.5,0.4)$ \\
\hline Bulgaria & $\mathcal{N}(-6.7,0.4)$ & Philippines & $\mathcal{N}(-7.9,0.4)$ \\
Colombia & $\mathcal{N}(-7.5,0.4)$ & Portugal & $\mathcal{N}(-7.2,0.4)$ \\
\hline Ecuador & $\mathcal{N}(-6.1,0.4)$ & RINTEMBIP & $\mathcal{N}(-7.6,0.4)$ \\
\hline Finland & $\mathcal{N}(-9.3,0.4)$ & Russia & $\mathcal{N}(-5.8,0.4)$ \\
\hline France & $\mathcal{N}(-9.3,0.4)$ & Slovenia & $\mathcal{N}(-7.9,0.4)$ \\
\hline GermanyRINT & $\mathcal{N}(-7.9,0.4)$ & South Africa & $\mathcal{N}(-8.2,0.4)$ \\
\hline Greece & $\mathcal{N}(-6.2,0.4)$ & Spain & $\mathcal{N}(-7.8,0.4)$ \\
\hline Indonesia & $\mathcal{N}(-7.8,0.4)$ & Turkey & $\mathcal{N}(-7.4,0.4)$ \\
\hline Ireland & $\mathcal{N}(-7.7,0.4)$ & Ukraine & $\mathcal{N}(-6.5,0.4)$ \\
\hline Italy & $\mathcal{N}(-7.7,0.4)$ & Venezuela & $\mathcal{N}(-6.7,0.4)$ \\
\hline Malta & $\mathcal{N}(-8.6,0.4)$ & & \\
\hline
\end{tabular}

Notes: Prior means and standard deviations are in parentheses, where $\mathcal{B}, \mathcal{N}$ and $\mathcal{N}^{+}$denote Beta, Normal and truncated Normal distributions. RINTEMBIP is the real (inflation expectations adjusted) 3-month U.S. T-Bill-it is the nominal version of this for which EMBI+ spreads are relative to. Sensitivity of priors was checked with respect to the following: (i) changing mean of $\eta_{r}$ prior from 0.5 to 0.25 ; (ii) changing mean and standard deviation of $\rho_{r}$ and $\rho_{\sigma_{r}}$ priors from $(0.9,0.02)$ to $(0.5,0.1)$ and from $(0.9,0.1)$ to $(0.5,0.2)$; (iii) combining (i) and (ii). These checks were also conducted for pre- and post-September 2008 samples.

Table 3 presents logarithms of the marginal likelihoods and their numerical standard errors. As can be seen, the stochastic volatility model outperforms the Markov-switching model in nineteen out of twenty-nine cases. Interpreting the result for Slovenia for instance, based on the data, we favor the stochastic volatility model over the Markov-switching model at an odds ratio of $e^{7.5}$. Furthermore, the log marginal likelihoods display low standard deviations indicative of accurate estimation. The continuous stochastic volatility model is a better representative of time-varying volatility of spreads for most of our sample relative to the discrete Markov-switching model.

\subsection{Results}

While we observe a nonnegligible degree of heterogeneity in empirical results across countries, our analysis reveals a number of general patterns in the data. First, standard deviations of innovations to country spreads are large. Second, stochastic volatility of country spreads is substantial. Third, country spread levels and country spread volatility are highly persistent. Fourth, corresponding parameters for the real international risk-free rates are smaller in magnitude. Fifth, results are relatively robust to subsample analysis, in particular to the global financial crisis post September 2008. Results are also relatively robust to alternative selections of Bayesian priors for the parameters underlying the stochastic volatility processes. Sixth, contemporaneous correlations between country spread volatility and deviations of output, consumption and investment from respective trends reveal negative links. Seventh, country spread levels and volatilities are highly positively correlated. 
TA B LE 3 Marginal likelihoods

\begin{tabular}{|c|c|c|}
\hline Country & Stochastic Volatility & Markov-Switching \\
\hline Argentina & $\begin{array}{l}1156.8 \\
(0.05)\end{array}$ & $\begin{array}{l}1071.4 \\
(0.07)\end{array}$ \\
\hline Austria & $\begin{array}{l}1884.8 \\
(0.03)\end{array}$ & $\begin{array}{l}2032.9 \\
(0.05)\end{array}$ \\
\hline Belgium & $\begin{array}{l}1879.8 \\
(0.06)\end{array}$ & $\begin{array}{l}1861.4 \\
(0.08)\end{array}$ \\
\hline Brazil & $\begin{array}{l}1351.3 \\
(0.03)\end{array}$ & $\begin{array}{l}917.1 \\
(0.04)\end{array}$ \\
\hline Bulgaria & $\begin{array}{l}1361.8 \\
(0.04)\end{array}$ & $\begin{array}{l}1278.9 \\
(0.07)\end{array}$ \\
\hline Colombia & $\begin{array}{l}1063.3 \\
(0.03)\end{array}$ & $\begin{array}{l}731.1 \\
(0.05)\end{array}$ \\
\hline Ecuador & $\begin{array}{l}1130.4 \\
(0.03)\end{array}$ & $\begin{array}{l}1265.4 \\
(0.07)\end{array}$ \\
\hline Finland & $\begin{array}{l}1710.8 \\
(0.04)\end{array}$ & $\begin{array}{l}1919.2 \\
(0.05)\end{array}$ \\
\hline France & $\begin{array}{l}1923.1 \\
(0.04)\end{array}$ & $\begin{array}{l}1889.8 \\
(0.05)\end{array}$ \\
\hline GermanyRINT & $\begin{array}{l}1307.7 \\
(0.03)\end{array}$ & $\begin{array}{l}1249.6 \\
(0.05)\end{array}$ \\
\hline Greece & $\begin{array}{l}1219.9 \\
(0.12)\end{array}$ & $\begin{array}{l}1139.2 \\
(0.07)\end{array}$ \\
\hline Indonesia & $\begin{array}{l}505.8 \\
(0.02)\end{array}$ & $\begin{array}{l}917.4 \\
(0.05)\end{array}$ \\
\hline Ireland & $\begin{array}{l}1757.5 \\
(0.06)\end{array}$ & $\begin{array}{l}1711.3 \\
(0.07)\end{array}$ \\
\hline Italy & $\begin{array}{l}1787.3 \\
(0.09)\end{array}$ & $\begin{array}{l}1634.8 \\
(0.07)\end{array}$ \\
\hline Malta & $\begin{array}{l}461.2 \\
(0.03)\end{array}$ & $\begin{array}{l}375.2 \\
(0.08)\end{array}$ \\
\hline Mexico & $\begin{array}{l}1499.5 \\
(0.04)\end{array}$ & $\begin{array}{l}1479.6 \\
(0.05)\end{array}$ \\
\hline Netherlands & $\begin{array}{l}1926.5 \\
(0.02)\end{array}$ & $\begin{array}{l}2074.6 \\
(0.05)\end{array}$ \\
\hline Panama & $\begin{array}{l}1330.2 \\
(0.02)\end{array}$ & $\begin{array}{l}999.5 \\
(0.08)\end{array}$ \\
\hline Peru & $\begin{array}{l}1212.1 \\
(0.02)\end{array}$ & $\begin{array}{l}786.3 \\
(0.08)\end{array}$ \\
\hline
\end{tabular}


TAB LE 3 (Continued)

\begin{tabular}{|lll|}
\hline Country & Stochastic Volatility & Markov-Switching \\
\hline Philippines & 1114.7 & 787.9 \\
& $(0.03)$ & $(0.11)$ \\
\hline Portugal & 1405.8 & 1373 \\
& $(0.16)$ & $(0.06)$ \\
\hline RINTEMBIP & 1936.6 & 2380.9 \\
& $(0.09)$ & $(0.05)$ \\
\hline Russia & 1116.7 & 1147.2 \\
& $(0.09)$ & $(0.05)$ \\
\hline Slovenia & 469.8 & 462.3 \\
& $(0.02)$ & $(0.06)$ \\
\hline South Africa & 917.8 & 1089.1 \\
& $(0.03)$ & $(0.07)$ \\
\hline Spain & 1770.9 & 1642.4 \\
& $(0.09)$ & $(0.07)$ \\
\hline Turkey & 1024.1 & 1152.9 \\
& $(0.02)$ & $(0.07)$ \\
\hline Ukraine & 810.5 & 1085.8 \\
& $(0.04)$ & $(0.07)$ \\
\hline Venezuela & 1272.7 & 897.4 \\
\hline & $(0.03)$ & $(0.05)$ \\
\hline
\end{tabular}

Notes: Marginal likelihoods (logarithms) for baseline stochastic volatility model and two-state Markov-switching variance AR(1) model are computed as in Chib and Jeliazkov (2001) and Chib (1995), respectively, with numerical standard errors in parentheses below.

We next discuss each of these results in detail. Table 4 reports the medians of the posteriors of the model parameters across countries and the corresponding 95\% probability sets. In the benchmark model, the level and volatility of interest rates are uncorrelated. Table S2 in the supplementary appendix provides results under a positive correlation between the level and volatility of country spreads. We refer to benchmark results unless otherwise noted.

\subsection{1 | Average $S D$ of innovations to country spreads}

The average standard deviation of an innovation to country spreads $\sigma_{r}$ is generally large, although it varies across samples. In particular, $\sigma_{r}$ is small for most nonperipheral members of the euro area. With the exception of peripheral euro area economies, especially Greece, on average $\sigma_{r}$ is higher for emerging markets than for euro area countries. The parameter (in logs) ranges from -8.4 in South Africa to -6.1 and -6.0 in Russia and Argentina versus -9.8 in the Netherlands to -7.4 and -6.4 in Portugal and Greece. Given the sample periods, this is the distribution that one might expect for these countries. The numbers are indicative of a large degree of volatility in country spread data, though less than that in the four-country study of Fernández-Villaverde et al. (2011). In addition, our findings reveal heterogeneity in the degree of volatility in country spread data. 
TA B L E 4 Posterior medians

\begin{tabular}{|c|c|c|c|c|c|c|c|c|}
\hline & $\rho_{r}$ & 95\% Set & $\sigma_{r}$ & 95\% Set & $\rho_{\sigma_{r}}$ & 95\% Set & $\eta_{r}$ & 95\% Set \\
\hline \multicolumn{9}{|l|}{ EA sample } \\
\hline Austria & 0.92 & {$[0.89,0.94]$} & -9.56 & {$[-10.03,-9.07]$} & 0.95 & {$[0.88,0.99]$} & 0.19 & {$[0.12,0.30]$} \\
\hline Belgium & 0.95 & {$[0.94,0.97]$} & -9.25 & {$[-9.80,-8.48]$} & 0.97 & {$[0.92,0.99]$} & 0.20 & {$[0.13,0.30]$} \\
\hline Finland & 0.93 & {$[0.91,0.95]$} & -9.49 & {$[-10.00,-8.78]$} & 0.96 & {$[0.87,0.99]$} & 0.28 & {$[0.18,0.42]$} \\
\hline France & 0.94 & {$[0.92,0.96]$} & -9.52 & {$[-10.01,-8.81]$} & 0.97 & {$[0.90,0.99]$} & 0.21 & {$[0.13,0.33]$} \\
\hline GermanyRINT & 0.95 & {$[0.93,0.96]$} & -8.42 & {$[-8.71,-7.56]$} & 0.96 & {$[0.77,0.99]$} & 0.11 & {$[0.04,0.24]$} \\
\hline Greece & 0.99 & {$[0.99,0.99]$} & -6.38 & {$[-7.12,-5.62]$} & 0.99 & {$[0.98,0.99]$} & 0.30 & {$[0.22,0.42]$} \\
\hline Ireland & 0.98 & {$[0.97,0.99]$} & -7.94 & {$[-8.71,-7.19]$} & 0.99 & {$[0.97,0.99]$} & 0.17 & {$[0.11,0.25]$} \\
\hline Italy & 0.99 & {$[0.98,0.99]$} & -7.88 & {$[-8.59,-7.08]$} & 0.99 & {$[0.98,0.99]$} & 0.18 & {$[0.13,0.25]$} \\
\hline Malta & 0.92 & {$[0.89,0.95]$} & -8.80 & {$[-9.20,-8.31]$} & 0.85 & {$[0.55,0.99]$} & 0.20 & {$[0.02,0.58]$} \\
\hline Netherlands & 0.91 & {$[0.87,0.94]$} & -9.79 & {$[-10.23,-9.35]$} & 0.96 & {$[0.88,0.99]$} & 0.17 & {$[0.10,0.26]$} \\
\hline Portugal & 0.98 & {$[0.97,0.98]$} & -7.38 & {$[-8.14,-6.57]$} & 0.99 & {$[0.97,0.99]$} & 0.23 & {$[0.15,0.35]$} \\
\hline Slovenia & 0.91 & {$[0.88,0.94]$} & -7.96 & {$[-8.37,-7.46]$} & 0.82 & {$[0.52,0.98]$} & 0.31 & {$[0.14,0.54]$} \\
\hline Spain & 0.98 & {$[0.98,0.99]$} & -8.00 & {$[-8.72,-7.24]$} & 0.99 & {$[0.97,0.99]$} & 0.16 & {$[0.11,0.24]$} \\
\hline \multicolumn{9}{|l|}{ EMBIP sample } \\
\hline Argentina & 0.97 & {$[0.96,0.98]$} & -6.05 & {$[-6.64,-5.05]$} & 0.93 & {$[0.83,0.99]$} & 0.39 & {$[0.29,0.52]$} \\
\hline Brazil & 0.97 & {$[0.95,0.98]$} & -7.17 & {$[-7.69,-6.42]$} & 0.97 & {$[0.90,0.99]$} & 0.23 & {$[0.17,0.33]$} \\
\hline Bulgaria & 0.98 & {$[0.97,0.99]$} & -6.99 & {$[-7.66,-6.14]$} & 0.98 & {$[0.92,0.99]$} & 0.25 & {$[0.16,0.38]$} \\
\hline Colombia & 0.94 & {$[0.92,0.96]$} & -7.78 & {$[-8.16,-7.28]$} & 0.92 & {$[0.76,0.99]$} & 0.20 & {$[0.11,0.34]$} \\
\hline Ecuador & 0.96 & {$[0.94,0.97]$} & -6.62 & {$[-7.07,-6.03]$} & 0.89 & {$[0.78,0.97]$} & 0.46 & {$[0.35,0.62]$} \\
\hline Indonesia & 0.91 & {$[0.87,0.94]$} & -7.98 & {$[-8.47,-7.43]$} & 0.87 & {$[0.63,0.98]$} & 0.34 & {$[0.18,0.58]$} \\
\hline Mexico & 0.96 & {$[0.95,0.97]$} & -7.68 & {$[-8.23,-6.86]$} & 0.97 & {$[0.92,0.99]$} & 0.20 & {$[0.13,0.30]$} \\
\hline Panama & 0.93 & {$[0.90,0.95]$} & -8.13 & {$[-8.39,-7.83]$} & 0.83 & {$[0.54,0.97]$} & 0.27 & {$[0.13,0.47]$} \\
\hline Peru & 0.94 & {$[0.92,0.96]$} & -7.76 & {$[-8.14,-7.25]$} & 0.93 & {$[0.74,0.99]$} & 0.21 & {$[0.12,0.37]$} \\
\hline Philippines & 0.93 & {$[0.91,0.95]$} & -8.09 & {$[-8.36,-7.80]$} & 0.90 & {$[0.63,0.99]$} & 0.14 & {$[0.05,0.30]$} \\
\hline RINTEMBIP & 0.97 & {$[0.96,0.98]$} & -8.37 & {$[-8.88,-7.25]$} & 0.97 & {$[0.86,0.99]$} & 0.21 & {$[0.14,0.30]$} \\
\hline Russia & 0.98 & {$[0.98,0.99]$} & -6.08 & {$[-6.90,-5.20]$} & 0.99 & {$[0.96,0.99]$} & 0.28 & {$[0.20,0.39]$} \\
\hline South Africa & 0.92 & {$[0.89,0.95]$} & -8.39 & {$[-8.79,-7.93]$} & 0.92 & {$[0.73,0.99]$} & 0.24 & {$[0.14,0.39]$} \\
\hline Turkey & 0.93 & {$[0.90,0.95]$} & -7.65 & {$[-8.10,-7.12]$} & 0.95 & {$[0.81,0.99]$} & 0.19 & {$[0.11,0.32]$} \\
\hline Ukraine & 0.95 & {$[0.93,0.97]$} & -6.79 & {$[-7.42,-6.03]$} & 0.95 & {$[0.85,0.99]$} & 0.31 & {$[0.21,0.46]$} \\
\hline Venezuela & 0.95 & {$[0.93,0.97]$} & -6.97 & {$[-7.31,-6.56]$} & 0.89 & {$[0.78,0.97]$} & 0.31 & {$[0.21,0.43]$} \\
\hline
\end{tabular}

Notes: The euro area (EA) sample is on the top, while the emerging market (EMBIP) sample is on the bottom. 95\% probability sets in brackets. $\rho_{r}$ is the persistence of the interest rate level, $\sigma_{r}$ is the mean $(\log )$ volatility of the interest rate, $\rho_{\sigma_{r}}$ is the persistence of the ( $\log$ ) volatility and $\eta_{r}$ is the parameter influencing the degree of stochastic volatility.

\subsubsection{Stochastic volatility and concentration of 95\% Sets}

Examining the $95 \%$ posterior probability sets, apart from the parameter governing the degree of stochastic volatility $\eta_{r}$, we witness mostly tightly concentrated posteriors. With the exception of the Philippines, which has a lower $\eta_{r}$, country spreads display a substantial presence of stochastic 
volatility (large $\eta_{r}$ ). Notably the degree of $\eta_{r}$ differs greatly across countries. While on average $\eta_{r}$ is higher in emerging markets than the euro area, it is substantial for some euro area members, such as Greece, Finland and Slovenia. We note, however, that the sample period for Slovenia is shorter, which significantly magnifies its standard deviation and hence its probability set.

\subsection{3 | Persistence of levels and volatility}

For the most part, interest rate levels and corresponding volatilities are persistent (large $\rho_{r}$ and $\rho_{\sigma_{r}}$ ). The standard deviations of the posterior of $\rho_{r}$ are small (95\% probability sets mostly lie above approximately 0.9), while those for $\rho_{\sigma_{r}}$ are larger. So, posterior medians for $\rho_{\sigma_{r}}$ take a wider range of values. Most of these medians, nevertheless, are over 0.9, and even at the 2.5th percentile the persistence of the process is in range of 0.52 to 0.99 across countries. The typical posterior medians for $\rho_{r}$ and $\rho_{\sigma_{r}}$ across the full sample of countries are both 0.95 , implying a half-life of about 14 months. Typical medians for $\rho_{r}$ and $\rho_{\sigma_{r}}$ in the euro area are 0.95 and 0.97 , while the typical values in emerging markets are 0.95 and 0.93 . The smaller value of 0.93 implies a half-life of about 10 months, while the bigger value of 0.97 implies a half-life of about 23 months.

\subsection{4 | Real international risk-free rate and country-specific interpretations}

Relative to the real Bund (GermanyRINT), our risk-free rate for euro area members, all peripheral euro area countries exhibit more persistence in country spreads and volatility, $\rho_{r}$ and $\rho_{\sigma_{r}}$. The spreads of these countries are also characterized by higher average volatility $\sigma_{r}$ and stochastic volatility $\eta_{r}$. As for emerging markets, South Africa stands alone in displaying lower average volatility $\sigma_{r}$ than that observed for the real U.S. T-Bill (RINTEMBIP), our international risk-free asset for the emerging sample. Meanwhile, compared to the real U.S. T-Bill, most nations have less persistent country spreads and volatility, $\rho_{r}$ and $\rho_{\sigma_{r}}$, but higher degrees of stochastic volatility $\eta_{r}$.

Taking a country-specific approach to interpreting the results, let us consider Bulgaria and Spain. These economies represent median countries in their respective groups (emerging and euro area samples) with regard to the effects of standard deviation shocks to country spread levels and volatilities. Examining Bulgaria the posterior median of $\sigma_{r}$ implies that an innovation to the spread has an average (annualized) standard deviation of $120,000 \times \exp \left(\sigma_{r}\right) \approx 111$ basis points. We apply the loading factor of 120,000 to transform $\sigma_{r}$ into annualized basis points. A one standard deviation positive volatility shock multiplies the standard deviation of the innovation to the spread by a factor of $\exp \left(\eta_{r}\right) \approx 1.28$. So, if both the level and volatility of spreads experienced positive shocks the Bulgarian spread would jump by $120,000 \times \exp \left(\sigma_{r}+\eta_{r}\right) \approx 142$ points. In comparison, more volatile countries such as Ecuador and Russia have numbers that are as high as 253 and 363 points.

Focusing on Spain, one of the six euro area peripheral countries along with Cyprus, Greece, Ireland, Italy and Portugal, the posterior median of $\sigma_{r}$ implies that the innovation to the spread has an average (annualized) standard deviation of 40 basis points. A one standard deviation positive volatility shock multiplies the standard deviation of the innovation to the spread by a factor of 1.17. Therefore, if both the level and volatility of spreads experienced simultaneous positive shocks, the Spanish spread would jump by 47 basis points. In comparison the corresponding figure is 94 basis points for Portugal, which is one of the most volatile countries in the euro area sample. 


\subsubsection{Extensions}

We conduct robustness checks to examine the impact of the Great Recession and prior sensitivity analysis in Section 3.2 of the online appendix. Spreads for most euro area countries are more volatile on average since $2008 \mathrm{M} 8$ ( $\sigma_{r}$ rose), whereas the opposite appears to be true for many emerging countries. After $2008 \mathrm{M} 8$, stochastic volatility $\eta_{r}$ rises in most countries. In further robustness checks, we loosen the priors for the means and standard deviations of $\rho_{r}$ and $\rho_{\sigma_{r}}$ and the mean of $\eta_{r}$. Results are relatively robust in most cases.

Volatility is countercyclical. In Section 5 of the technical appendix, we plot smoothed estimates of country spread volatility against measures of aggregate economic activity. Volatility correlates negatively with business cycle fluctuations, consistent with the notion that greater uncertainty has an adverse impact on economic activity. Other than the trade balance, there tends to be a negative correlation between macro aggregates and country-spread levels. To rationalize declining debt with higher interest rate spreads and volatility, we observe that the trade balance correlates positively with both interest rate spreads and their volatility. Trade surpluses export excess savings of a country, for instance an increase in foreign debt asset purchases relative to foreign debt liabilities. ${ }^{14}$ These empirical results serve to further motivate the quantitative exploration in this paper.

Finally, country spread levels and their volatilities are strongly positively correlated as evidenced in Section 5 of the technical appendix. Table S2 in the technical appendix presents the results from a more elaborate model allowing correlation between innovations to the country spread and innovations to the volatility of the spread. Overall the correlation parameter, which is the size of the leverage effect of the observed level shocks on the log volatility shocks, tends to be rather high for country spreads, but it still exhibits a nonnegligible degree of heterogeneity across countries. Correlations are generally higher for emerging markets. Consequently, level and volatility innovations move and affect the economy in the same direction in causal analyses. Keeping the zero correlation case as the benchmark, nevertheless, we can still isolate the direct effects of changes in volatility while holding the level of interest rates constant.

\section{3 | A QUANTITATIVE-THEORETICAL ANALYSIS}

\section{1 $\quad$ Theoretical model}

The representative household has expected lifetime utility

$$
E_{0} \sum_{t=0}^{\infty} \beta^{t}\left(\frac{C_{t}^{1-\nu}}{1-v}-\omega \frac{H_{t}^{1+\eta}}{1+\eta}\right)
$$

where $C_{t}$ is consumption, $H_{t}$ is labor, $\beta \in(0,1)$ is the discount factor, $\nu$ governs the intertemporal elasticity of substitution in consumption, and $\eta$ mediates the Frisch elasticity of labor supply. The household faces a flow budget constraint in each period, namely,

$$
\frac{D_{t+1}}{1+r_{t}}=D_{t}-W_{t} H_{t}-R_{t} K_{t}+C_{t}+I_{t}+\frac{\Phi_{D}}{2}\left(D_{t+1}-D\right)^{2}
$$

where $D_{t}$ denotes debt holdings in the form of an internationally traded bond, $D$ determines debt in the deterministic steady state, $K_{t}$ is the stock of physical capital, $I_{t}$ is gross capital investment, $r_{t}$ is the real 
interest rate, $W_{t}$ is the real wage, $R_{t}$ is the rental rate on capital, and $\Phi_{D}>0$ mediates the cost of net external debt adjustment. ${ }^{15}$ Capital accumulates according to the equation

$$
K_{t+1}=(1-\delta) K_{t}+\left(1-\frac{\phi}{2}\left(\frac{I_{t}}{I_{t-1}}-1\right)^{2}\right) I_{t}
$$

where $\phi>0$ influences the size of the capital adjustment costs and tempers the investment volatility in response to real interest rate changes for small open-economy models. The standard transversality condition holds for the maximization problem of the household.

On the production side, firms turn capital and labor into a final homogeneous good according to the production function

$$
Y_{t}=K_{t}^{\alpha}\left(e^{X_{t}} H_{t}\right)^{1-\alpha}
$$

in which labor-augmenting technology evolves according to

$$
X_{t}=\rho_{X} X_{t-1}+\sigma_{X} u_{X, t} \quad u_{X, t} \sim \mathcal{N}(0,1) .
$$

The parameter $\alpha \in(0,1)$ denotes the capital intensity. We note that the current account $\left(C A_{t}\right)$ is the change in the net external debt position

$$
C A_{t}=D_{t}-D_{t+1}
$$

and that the budget constraint in (6) can be rewritten to yield an expression for net exports $\left(N X_{t}\right)$

$$
N X_{t}=Y_{t}-C_{t}-I_{t}=D_{t}-\frac{D_{t+1}}{1+r_{t}}+\frac{\Phi_{D}}{2}\left(D_{t+1}-D\right)^{2}
$$

Once again the dynamics of the real interest rate $r_{t}$ faced by domestic residents in financial markets are governed by Equations (1)-(5). We consider two versions of our model. The first version assumes a zero correlation between the level and volatility of interest rates (M1), while the second version assumes a nonzero level-volatility correlation in interest rates (M2).

\subsection{Computation: Solution and estimation}

Our paper improves upon the computational procedures outlined in the literature. To isolate the effect of volatility, we use a third-order perturbation solution method. ${ }^{16}$ We apply a simulated method of moments procedure modifying Dynare codes from Born and Pfeifer (2014) on solution and Andreasen et al. (2018) on pruning. Using analytical solutions for the theoretical ergodic mean, we winsorize country spread level and volatility shocks, but leave technology shocks unwinsorized. ${ }^{17,18} \mathrm{We}$ then simulate the model from the ergodic mean. This step improves upon the computations of previous studies by using the ergodic mean rather than the ergodic mean in the absence of shocks to start the simulation in which all variables are subjected to efficient pruning. ${ }^{19,20}$

We correct for time aggregation issues raised by Born and Pfeifer (2014). Mixed frequency data is common in international finance. As the simulated data is at monthly frequency, we aggregate to 
quarterly frequency to match empirical moments. For variables expressed in percentage deviations from their ergodic means, the average rather than the summation is the correct transformation. Some measures, however, such as the net exports to output ratio, do not require aggregation. We estimate model moments over 96 periods and obtain the mean over 3,000 simulations, which yields the ergodic mean of each model moment. We find that 3,000 periods are sufficient for convergence of model moments. Section 7 of the online appendix discusses details of the grid search procedure.

As net exports can be negative, Correia, Neves, and Rebelo (1995) use the expression NX/NXI-1 for percentage growth deviations of net exports, which can be HP filtered. ${ }^{21}$ This measure, however, is numerically unstable, especially when net exports are almost zero. We focus on the net export share of output. Rather than the ratio of the volatilities of net exports and output, and the correlation between net exports and output, we focus on the volatility of the net export share of output and the correlation between this ratio and output. We only HP filter the ratio of net exports to output $N X / Y$ when computing the first-order autocorrelation between this ratio and output and the volatility of this ratio. We do not filter $N X / Y$ when computing the mean of $N X / Y$ used for moment matching in the calibration. We report the sample periods for each country in Table 2 and the empirical moments in Section 6 of the technical appendix. The empirical and theoretical moments for net exports are underreported by a factor of 100 in Fernández-Villaverde et al. (2011), but are corrected in our paper.

In estimating the response functions of control variables, standard orthogonalized impulse response functions (IRFs) are inappropriate because of the nonlinearities in the model (Koop, Pesaran, \& Potter, 1996). We improve upon past studies by estimating generalized IRFs (GIRFs) at the true ergodic mean. ${ }^{22}$ In particular, we employ the second version of GIRFs from the technical appendix of Andreasen et al. 2018, p. 182) defined as $\operatorname{GIRF}_{\mathbf{v a r}}\left(l, v_{i}, \mathbf{w}_{t}\right)=\mathbb{E}_{t}\left[\mathbf{v a r}_{t+l} \mid v_{i}\right]-\mathbb{E}_{t}\left[\mathbf{v a r}_{t+l}\right]$ for a disturbance to innovation $i{ }^{23}$ From this definition, we can see that these GIRFs are expressed as absolute deviations from the ergodic means.

When a variable is logarithmically transformed, multiplying the GIRF by 100 will result in a GIRF that can be interpreted in percentage deviations from the ergodic mean. We convert GIRFs for the country interest rate spread $\epsilon_{r, t}$ into annualized basis points by multiplying the GIRF by the loading factor of $12 \times 100 \times 100$. As the ergodic mean for the country interest rate spread is zero, we can interpret impulse responses for country interest rate spreads in annualized basis points. The variable will depart from zero following interest spread level shocks for instance before gradually returning back toward zero, with duration depending positively on the persistence of the country interest rate. We express the GIRF for each other variable as the percentage deviation from its ergodic mean. To express the response of debt in percentage deviations from its ergodic mean we need to adjust the GIRF for debt (a level variable) by dividing it by the ergodic mean for debt and multiplying it by 100 . Once adjusted, all resulting GIRFs are aggregated to quarterly frequency by averaging the adjusted monthly GIRFs.

\section{3 | Parameter calibration}

We use the long, broad samples of our paper and follow the computational improvements described in Section 3.2 to calibrate two versions of the model for each of the 26 countries: the baseline and augmented cases, denoted by M1 and M2. In line with the data, we calibrate the parameters at monthly frequency. We subsequently convert model data in simulations from monthly to quarterly frequency so that all results are reported on a quarterly basis. Six parameters are fixed across countries as follows: $\left\{v, \eta, \delta, \alpha, \rho_{X}\right\}=\{5,1000,0.014,0.32,0.95,1\}$. Table $\mathrm{S} 27$ in the online appendix lists 
country-specific calibrations. In addition, $\beta=(1+r)^{-1}$ is country-specific, where $r$ is the mean net real interest rate for each country and is reported in Table $\mathrm{S} 1$ of the online appendix. The parameters for the laws of motion for country spread deviations and real international risk-free rate deviations along with their volatilities, including the level-volatility correlation parameter $\kappa$ in the augmented model, are taken from the medians of the posterior distributions. ${ }^{24}$

For the final four parameters $\sigma_{X}, \phi, D, \Phi_{D}$, the ergodic distribution of the model moments matches the four empirical moments $\sigma_{Y}, \frac{\sigma_{C}}{\sigma_{Y}}, \frac{\sigma_{I}}{\sigma_{Y}}, \frac{N X}{Y}$. We select these four parameters through a simulated method of moments procedure to minimize an equally weighted quadratic loss function of the distance between the model moments and those of the data. Since higher order approximations shift the ergodic mean of endogenous variables away from the deterministic steady states, we calibrate parameters according to ergodic moments rather than those in steady state. Empirical moments correspond to quarterly data which were converted to real values, seasonally adjusted with the U.S. Census Bureau's X12-ARIMA program, and HP filtered. Similarly, we adjust the simulated series by applying the HP filter. $^{25,26}$

In contrast to previous research, we allow the external debt adjustment cost parameter $\Phi_{D}$ to move freely in order to narrow the gap between model moments and empirical moments. ${ }^{27}$ This parameter is higher in this model for most countries than the typical values reported by Uribe and Yue (2006), Fernández-Villaverde et al. (2011), and Born and Pfeifer (2014). While in the literature higher $\Phi_{D}$ and $\sigma_{X}$ appear with higher consumption and output volatility, we find no strong relation. Both the baseline (M1) and augmented (M2) models do a good job of matching the moments in the data, with only a couple of exceptions. Regardless of the choice of parameter values, standard small open economy models have difficulties in accounting for the data.

\subsection{Generalized impulse response functions: Volatility shocks}

Section 8.1 of the online appendix plots GIRFs. Creditors are countries for whom the mean of debt in the ergodic distribution is negative. That is, creditors have negative net external debt on average with external debt assets exceeding liabilities. The level shocks depicted in the first rows put into context the size of GIRFs to volatility shocks in the second row for each country. ${ }^{28}$ The domestic interest rate faced by the country and its expected value are fixed. In response to the volatility shock, we observe (a) a fall (mostly) in consumption, (b) a decline (mostly) in investment with a longer period until investment stops falling associated with higher adjustment costs of capital, (c) a decrease (mostly) in output, (d) a small rise (mostly) in labor initially that falls later and (e) a contraction (mostly) of debt (or positive assets) upon impact that declines persistently before rising, although this persistence in debt reduction tends to be higher for countries with lower costs of net foreign debt adjustment $\Phi_{D}$ and is also influenced positively by capital adjustment costs $\phi$. In contrast to the literature, some countries exhibit expansions in investment and output following a volatility shock. ${ }^{29}$ The GIRFs highlight how increases in risk have real effects on the economy, even when the interest rate is held constant. ${ }^{30,31}$

In response to a one standard deviation shock to country spread volatility, consumption drops on impact by up to $1.19 \%$ (Russia [EMBIP]) or $0.42 \%$ (Greece [EA]). Investment falls by up to $2 \%$ (Argentina [EMBIP]) or $0.6 \%$ (Italy [EA]). Output declines by about $1 \%$ (Argentina) or $0.6 \%$ (Italy). Debt reduces by up to $3.5 \%$ (Bulgaria [EMBIP]) or $2.7 \%$ (Italy). To put the size of the shock into perspective, consider the case of Ireland, which is a conservative representation of the euro area periphery. The global financial crisis meant from May 2008 to January 2009 there was a positive volatility shock of about four standard deviations, while the European sovereign debt crisis amounted to two 
repeated shocks, January 2010 to July 2010 and August 2010 to December 2010 of about 2 and 1.5 standard deviations. ${ }^{32}$

For the study of Argentina, Brazil, Ecuador and Venezuela pre-2008M2 in Fernández-Villaverde et al. (2011), the authors use the first-order condition with respect to $D_{t+1}$ to dissect the precautionary behavior mechanism underlying the effects of country spread volatility shocks:

$$
\frac{1}{1+r_{t}}-\beta \mathbb{E}_{t} \frac{\lambda_{t+1}}{\lambda_{t}}=\Phi_{D}\left(D_{t+1}-D\right)
$$

In contrast to that study, while volatility shocks do not affect $r_{t}$, it is not necessarily the case that $\mathbb{E}_{t} \frac{\lambda_{t+1}}{\lambda_{t}}$ always increases. To understand this implication, consider the following argument.

The marginal utility of consumption, $\lambda_{t}$, is convex because third-order terms are determined by the fourth derivative of the utility function that has to be positive for households to lower debt in response to volatility shocks. Higher real interest rate volatility will increase the future volatility of consumption. With more uncertainty regarding future consumption, convex marginal utility will then imply an increase in $\mathbb{E}_{t} \lambda_{t+1}$. When consumption falls upon impact, calibration will determine which effect dominates: the rise in $\mathbb{E}_{t} \lambda_{t+1}$ or the rise in $\lambda_{t}$. The calibration of Fernández-Villaverde et al. (2011) always implies that the rise in $\mathbb{E}_{t} \lambda_{t+1}$ dominates the rise in $\lambda_{t}{ }^{33}$ In contrast, we find some countries where consumption rises upon impact, in particular for certain creditors, which unambiguously raises $\mathbb{E}_{t} \lambda_{t+1} / \lambda_{t}$. Furthermore, GIRFs for debt in our paper are expressed as percentage deviations from its ergodic mean by dividing by the ergodic mean for debt. ${ }^{34}$ Thus, we distinguish between the following cases. If consumption rises upon impact, creditors will take on more debt assets (relative to liabilities), whereas debtors will reduce their debt liabilities (relative to assets). The results will be the same if consumption falls upon impact and the $\mathbb{E}_{t} \lambda_{t+1}$ effect dominates. When calibration suggests that the $\lambda_{t}$ effect dominates, creditors will reduce their debt assets (relative to liabilities), whereas debtors will take on more debt liabilities (relative to assets). ${ }^{35}$

Thus, if the ratio of expected marginal utility for tomorrow's consumption to today's marginal utility rises, debt liabilities fall relative to assets. Creditors expose themselves to more debt assets while debtors decumulate debt liabilities. For such countries, debtors fear paying potentially higher interest on their debt liabilities yet creditors are willing to potentially benefit from future higher interest rates on their debt assets. The opposite occurs if the ratio of marginal utilities declines.

\section{CONCLUSION}

This paper investigates the relation between real interest rate volatility and macroeconomic performance for a diverse set of countries. We find the stochastic volatility model to be a better representative of the time-varying volatility of spreads than the discrete Markov-switching model. We also obtain unequivocal evidence indicating that stochastic volatility shocks to real interest rate spreads are rather large and persistent overall, with estimates exhibiting non-negligible cross-country heterogeneity. Moreover, some advanced economies are more volatile than emerging markets.

We subsequently demonstrate that the observed empirical regularities can be reproduced by a standard equilibrium business cycle model augmented with stochastic interest rate volatility shocks. Our heterogeneous sample and improved computational procedures enable us to identify new nuances in analyzing and interpreting how risk shocks can affect the macroeconomy. For instance, creditors can take on more debt following volatility shocks. Computationally, our paper makes advances in 
performance and accuracy through the use of shell scripting, high-level parallelism, new results on third-order pruning in state-space models, and recommendations proposed by Born and Pfeifer (2014).

Quantifying changes in real interest rate volatility and its interaction with business cycle fluctuations further enhances our understanding of the international financial macroeconomy. In particular, our analysis of the impact of interest rate volatility shocks on aggregate economic outcomes should assist policymakers in the formulation of more effective macroeconomic interventions. In addition, the wealth of empirical findings in this paper across a wide-ranging sample of countries will be of interest to academics aiming to incorporate interest rate uncertainty into alternative stochastic frameworks of the macroeconomy.

\section{ACKNOWLEDGMENTS}

We thank the Irish Research Council for financial support. We are grateful to Benjamin Born, Jesús Fernández-Villaverde, Philip Lane, Enrique Mendoza, Paul Scanlon, Frank Warnock, and Michael Wycherley for helpful comments and suggestions. A technical appendix can be found at https://ae9e5 d40-a-62cb3a1a-s-sites.googlegroups.com/site/adnvelic/research/Risk_App.pdf. The data and code that support the main findings of this study are openly available at https://michael-curran.com/resea rch/RiskCode.zip.

\section{DATA AVAILABILITY STATEMENT}

The data and code that support the main findings of this study are openly available at https://michaelcurran.com/research/RiskCode.zip.

\section{ORCID}

Michael Curran (iD http://orcid.org/0000-0001-5673-0182

\section{ENDNOTES}

${ }^{1}$ In broader terms, until the last two decades, macroeconomists paid little attention to the impact of uncertainty and volatility on macroeconomic performance (Hamilton, 2008, p. 2).

${ }^{2}$ On computation, Born and Pfeifer (2014) discuss technical issues arising from earlier work on this subject.

${ }^{3}$ We also assume long-run NFA positions to be exogenous. Many of our countries are characterized by persistent NFA positions, that is, are either creditors or debtors for long periods. As Chinn and Prasad (2003) indicate, most of the variation in NFAs in panel studies comes from the cross-sectional dimension rather than the time dimension.

${ }^{4}$ The EMBI+ is an interest rate that proxies the cost of international borrowing for emerging markets. EMBI+ tracks secondary market prices of actively traded emerging market bonds denominated in US dollars in units of percent per annum (not seasonally adjusted), that is, total returns for traded external debt instruments in emerging markets (external meaning foreign currency denominated fixed income). EMBI+ covers US dollar-denominated Brady bonds, loans and Eurobonds with an outstanding face value of at least $\$ 500$ million. See Neumeyer and Perri (2005) for further discussion on the EMBI+.

${ }^{5}$ Taking the average during the month instead does not alter our findings.

${ }^{6}$ Alternative interpolation procedures, such as cubic spline approximations, do not significantly alter our results.

${ }^{7}$ Tables S1 and S26 of the online appendix detail country-specific time coverage for the interest rates and for the NIPA data employed in Sections 2 and 3 of the main paper. Section 1 of the online appendix provides further information on the preparation of the data.

${ }^{8}$ With the international risk-free rate, we estimate one process for emerging markets and one for advanced nations.

${ }^{9}$ Fixed across countries, priors for $\rho_{r}, \rho_{\sigma_{r}}$, and $\eta_{r}$ are $\mathcal{B}(0.9,0.02), \mathcal{B}(0.9,0.1)$, and $\mathcal{N}^{+}(0.5,0.3) . \mathcal{B}$ and $\mathcal{N}^{+}$denote Beta and truncated Normal distributions. Means and standard deviations are given within parentheses. 
${ }^{10}$ See Fernández-Villaverde et al. 2011, p. 2537-2538) for a discussion on prior elicitation reflecting conservative choices.

${ }^{11}$ We focus on parametric models since we feed parametric estimates into a DSGE model.

${ }^{12}$ Reyes-Heroles and Tenorio (2019) conduct an insightful investigation on the relation between interest rate volatility and sudden stops using a multi-country bivariate regime-switching VAR model. They interpret country time series as independent draws from a stochastic process with the same parameters $\boldsymbol{\theta}$. We allow the parameters $\boldsymbol{\theta}$ to change internationally reflecting countries' heterogeneous responses. Estimating country-specific time series rather than panel data provides us more freedom to exploit our sample's heterogeneity.

${ }^{13}$ Section 4 of the online appendix details the estimation strategy and the marginal likelihood computation.

${ }^{14}$ In line with Fernández-Villaverde et al. (2011), we define net foreign debt as debt liabilities net of debt assets.

${ }^{15}$ Closing the small open economy model, that is, inducing stationarity in the model from otherwise unit root dynamics, with an adjustment cost of debt $\Phi_{D}$ as in the benchmark model is a conservative modeling choice because it reduces the effects of volatility. Section 9 of the online appendix compares alternative methods of inducing stationarity.

${ }^{16}$ Alternative methods include closed-form solutions and solutions involving lower order approximations for incorporating stochastic volatility in DSGE models; see for instance de Groot (2015). To relate our results more closely to the work by Fernández-Villaverde et al. (2011) and Born and Pfeifer (2014), we do not adopt these techniques.

${ }^{17}$ We reduce computation time by avoiding unnecessarily computing the theoretical ergodic variance-covariance matrix, which takes five minutes. In contrast, computing the theoretical ergodic mean takes less than a second.

${ }^{18}$ Convergence of simulated moments toward corresponding ergodic means was improved by truncating shocks to be less than one in absolute value.

${ }^{19}$ This step addresses the issues raised by Born and Pfeifer (2014) in Section V of their technical appendix.

${ }^{20}$ We tested starting the simulations at the ergodic mean each time for 96 periods with various burn-in periods. Altering the number of burn-in periods made no significant difference to computed moments as draws already came from the ergodic distribution, negating the necessity of having a burn-in, thereby reducing the run-time.

${ }^{21}$ We get net export data from the IMF's IFS. We drop Panama since quarterly frequency data is unavailable.

${ }^{22}$ In contrast to our approach, computing the GIRFs at the ergodic mean in the absence of shocks only captures part of the economic effects of risk shocks. When making decisions, furthermore, households will account for the past and future absence of shocks. Taken together, households will hold higher levels of debt than they may otherwise.

${ }^{23}$ The formulae derived from this definition allow for the joint effects of multiple shocks.

${ }^{24}$ Table 4 contains posterior medians for the baseline model, while Table S2 in the online appendix contains posterior medians for the augmented model.

${ }^{25}$ Results from using other filtering methods such as the bandpass filter were almost identical to results from using the HP filter with a tuning parameter of $\lambda=1600$.

${ }^{26}$ Further details on parameter calibration by grid search are relegated to Section 7 of the online appendix.

${ }^{27}$ Moments and variance decompositions are relegated to Section 8 of the supplementary appendix.

${ }^{28}$ To focus on volatility shocks, we relegate our discussion of level shocks to Section 8.1.1. of the online appendix.

${ }^{29}$ The New Keynesian model is necessary for volatility to always generate recessions (Basu \& Bundick, 2017).

${ }^{30}$ Results are qualitatively robust to allowing for correlation between level and volatility innovations. Differences reflect both the interaction of level and volatility shocks and distinct calibrations for M1 and M2.

${ }^{31}$ For extensive comparisons of our results to earlier studies of Fernández-Villaverde et al. (2011) and Born and Pfeifer (2014), the interested reader may consult Section 15 of the online appendix.

${ }^{32}$ For more on the quantitative implications of the estimated theoretical model, Sections 10-15 of the online appendix detail a battery of extensions to the main results.

${ }^{33}$ In their working paper version, the authors conduct a counterfactual experiment in row 4 of Figure 13, where it is evident in one case that the opposite holds.

${ }^{34}$ Tables S66-S91 in the online appendix show that steady states and ergodic means share the same sign.

${ }^{35}$ Positive GIRFs mean taking on relatively more debt (assets for creditors, liabilities for debtors) and vice-versa. 


\section{REFERENCES}

Aizenman, J., Hutchison, M., \& Jinjarak, Y. (2013). What is the risk of European sovereign debt defaults? Fiscal space, CDS spreads and market pricing of risk. Journal of International Money and Finance, 34, 37-59.

Akíncí, Ö. (2013). Global financial conditions, country spreads and macroeconomic fluctuations in emerging countries. Journal of International Economics, 91(2), 358-371.

Andreasen, M. M., Fernández-Villaverde, J., \& Rubio-Ramírez, J. (2018). The pruned state-space system for non-linear DSGE models: Theory and empirical applications. Review of Economic Studies, 85(1), 1-49.

Ardagna, S., Caselli, F., \& Lane, T. (2007). Fiscal discipline and the cost of public debt service: Some estimates for OECD countries. The B.E. Journal of Macroeconomics, 7, 1-35.

Baker, S. R., Bloom, N., \& Davis, S. J. (2016). Measuring economic policy uncertainty. The Quarterly Journal of Economics, 131(4), 1593-1636.

Balli, F. (2009). Spillover effects on government bond yields in Euro zone. Does full financial integration exist in European government bond markets? Journal of Economics and Finance, 33(4), 331-363.

Barrios, S., Iversen, P., Lewandowska, M., \& Setzer, R. (2009). Determinants of intra-Euro area government bond spreads during the financial crisis (Technical report, Directorate General Economic and Financial Affairs (DG ECFIN), European Commission, Economic Papers). European Commission: Directorate General Economic and Financial Affairs.

Basu, S., \& Bundick, B. (2017). Uncertainty shocks in a model of effective demand. Econometrica, 85(3), 937-958.

Born, B., \& Pfeifer, J. (2014). Risk matters: The real effects of volatility shocks: Comment. American Economic Review, 104(12), 4231-4239.

Chib, S. (1995). Marginal likelihood from the Gibbs output. Journal of the American Statistical Association, 90(432), 1313-1321.

Chib, S., \& Jeliazkov, I. (2001). Marginal likelihood from the Metropolis-Hastings output. Journal of the American Statistical Association, 96(453), 270-281.

Chinn, M. D., \& Prasad, E. S. (2003). Medium-term determinants of current accounts in industrial and developing countries: An empirical exploration. Journal of International Economics, 59(1), 47-76.

Codogno, L., Favero, C., \& Missale, A. (2003). Yield spreads on EMU government bonds. Economic Policy, 18(37), 503-532.

Correia, I., Neves, J. C., \& Rebelo, S. (1995). Business cycles in a small open economy. European Economic Review, 39(6), 1089-1113.

Curran, M., \& Velic, A. (2020). The CAPM, national stock market betas, and macroeconomic covariates: A global analysis. Open Economies Review, 1-34. https://link.springer.com/article/10.1007/s11079-020-09579-2

de Groot, O. (2015). Solving asset pricing models with stochastic volatility. Journal of Economic Dynamics and Control, 52(C), 308-321.

Eijffinger, S. C., Kobielarz, M. L., \& Uras, B. (2015). Sovereign debt, bail-outs and contagion in a monetary union (Technical Report No. 10459, CEPR Discussion Papers). London: CEPR.

Fahr, S., Motto, R., Rostagno, M., Smets, F., \& Tristani, O. (2013). A monetary policy strategy in good and bad times: Lessons from the recent past. Economic Policy, 28(74), 243-288.

Favero, C., \& Missale, A. (2012). Sovereign spreads in the Eurozone: Which prospects for a Eurobond? Economic Policy, 27(70), 231-273.

Fernández-Villaverde, J., Guerrón-Quintana, P., Rubio-Ramírez, J., \& Uribe, M. (2011). Risk matters: The real Effects of volatility shocks. American Economic Review, 101(6), 2530-2561.

García-Cicco, J., Naudon, A., \& Heresi, R. (2013). The real effects of global risk shocks in small open economies (Technical report, Central Bank of Chile Working Paper). Santiago: Central Bank of Chile

Hamilton, J. (2008). Macroeconomics and ARCH (NBER Working Papers No. 14151, NBER Working Papers). Cambridge MA: NBER.

Koop, G., Pesaran, H., \& Potter, S. (1996). Impulse response analysis in nonlinear multivariate models. Journal of Econometrics, 74(1), 119-147.

Lane, P. R., \& Milesi-Ferretti, G. M. (2007). The external wealth of nations mark II. Journal of International Economics, 73(2), 223-250.

Laubach, T. (2009). New evidence on the interest rate effects of budget deficits and debt. Journal of the European Economic Association, 7(4), 858-885. 
Leduc, S., \& Liu, Z. (2016). Uncertainty shocks are aggregate demand shocks. Journal of Monetary Economics, 82, $20-35$.

Longstaff, F. A., Pan, J., Pedersen, L. H., \& Singleton, K. J. (2011). How sovereign is sovereign credit risk? American Economic Journal: Macroeconomics, 3(2), 75-103.

Ludvigson, S. C., Ma, S., \& Ng, S. (2015). Uncertainty and business cycles: Exogenous impulse or endogenous response? (Technical Report No. 21803, NBER Working Paper). Cambridge MA: NBER

Mody, A., \& Sandri, D. (2012). The Eurozone crisis: How banks and sovereigns came to be joined at the hip. Economic Policy, 27(70), 199-230.

Neumeyer, P., \& Perri, F. (2005). Business cycles in emerging economies: The role of interest rates. Journal of Monetary Economics, 52(2), 345-380.

Reyes-Heroles, R., \& Tenorio, G. (2019). Regime-switching in emerging market business cycles: Interest rate volatility and sudden stops. Journal of International Money and Finance, 93, 81-100.

Uribe, M., \& Yue, V. (2006). Country spreads and emerging countries: Who drives whom? Journal of International Economics, 69(1), 6-36.

Von Hagen, J., Schuknecht, L., \& Wolswijk, G. (2011). Government bond risk premiums in the EU revisited: The impact of the financial crisis. European Journal of Political Economy, 27(1), 36-43.

\section{SUPPORTING INFORMATION}

Additional Supporting Information may be found online in the Supporting Information section.

How to cite this article: Curran M, Velic A. Interest rate volatility and macroeconomic dynamics: Heterogeneity matters. Rev Int Econ. 2020;28:957-975.

https://doi.org/10.1111/roie.12477 